\title{
Cultivation of Intercultural Communication Ability in English Teaching under the Background of "Culture Going-Out” Strategy
}

\author{
Xushan Ruan \\ Ankang University, Ankang, 725000, China
}

Keywords: Culture going-out; English teaching; Intercultural communication competence; cultivation

\begin{abstract}
In order to respond to the $18^{\text {th }}$ National Congress of CPC, "Culture Going-Out" is a strategic goal in the near future. All walks of life in China need cross-cultural communication talents, and should pay attention to the cultivation of intercultural competence and compound talents. Not only should we focus on the teaching of English knowledge, it is necessary to cultivate students' intercultural communication skills, which is of great significance to the future development of students.
\end{abstract}

\section{Introduction}

With the convening of the "18th National Congress of the Communist Party of China", China has proposed national development strategies such as "going out of culture" and "taking all the way", with the aim of expanding China's exchanges, promoting Chinese culture, and enhancing China's global appeal. The influence will enable China's soft power to be improved and the dream of a strong nation of the great rejuvenation of the Chinese nation to be realized. In order to realize China's ambitious goals, China needs to train a group of comprehensive high-quality talents with intercultural communication skills. At present, China has already issued relevant laws and regulations on cultural education, and English teaching is one of the important tasks. The study of language is inextricably linked with culture and environment. The cultivation of students' intercultural communication ability in the process of English learning not only enhances students' English ability, but also enables students to understand international culture and has a future development for students.

\section{The concept of intercultural communication competence}

Communication between two different languages also means that there is a difference in any cultural background. Communication between people is called intercultural communication. In other words, the sender and recipient of the message can communicate between different races, different ethnic groups, and different countries. Cross-culture can cover a wide range, such as customs, thinking, values, etc. Some scholars refer to it as a social phenomenon and historical phenomenon, 
which is the trace left by human beings in social development ${ }^{[1]}$. In today's world, culture is developing in a diversified direction. Although there are coincident parts in different cultures, there are still some differences. In order to achieve globalization, we must master cross-cultural communication skills. It can be seen that comprehensive talents that cultivate communicative competence have become an inevitable trend in China's development.

\section{The theoretical background}

\subsection{The relationship between language and culture}

Language is an important part of culture. It can be said that in the process of human evolution, it is an important spiritual wealth created by human beings. Culture and language are both an ability to learn from the day and are an inseparable part. Language is the carrier of culture. Through language, one country can be seen. The history and spirit of a nation can be revealed. The relationship between language and culture is very close and can promote each other and influence each other. The text can record the changing process of an era, no matter how good or bad can be reflected. With the continuous development of the times, a large number of vocabulary has emerged, which has gradually enriched the language.

\subsection{Intercultural communication competence}

After a lot of scholars' research, it is found that the factors that interfere with people's communicative competence are not only language ability, but also cultural factors. For example, in first meeting, people from Western countries express their greetings by hugs and kisses, while people from Asian countries shake hands with each other. In order to achieve effective communication, in addition to mastering relevant language skills, it is also necessary to understand relevant cultures in order to ensure the effectiveness of communication between people of different races and regions.

\section{The elements of cultivating intercultural communication competence}

In order to improve the intercultural communication ability of students in English teaching, we should change the traditional teaching methods, use multiple channels of teaching, collect cultural information of English countries, and enable students to understand the cultural knowledge of the countries behind the English language, and finally improve the students' intercultural communication skills.

\subsection{Improve students' awareness of intercultural communication competence}

Attention should be paid to the cultivation of students' cross-cultural awareness and awareness-oriented actions. Therefore, only students can strengthen their cross-cultural communication awareness, so that students can understand the relevant culture in English learning, and enable students to face a variety of sources of information, effectively winnow truth from falsehood, and retain its essence. The change of consciousness enables students to learn more deeply about language culture and mother tongue culture, and to reduce the influence of mother tongue culture on English learning ${ }^{[2]}$. English teachers should use the principle of practicality in the teaching process to gradually increase the content of students' learning. It should be based on the principle of gradual improvement, so that students can understand the English cultural background. Specifically, we can start from the following four aspects: 
Strengthening the cultural background, in the process of English teaching, teachers can inquire about the corresponding customs and customs of Western countries according to the content of the lesson, and introduce the humanities knowledge of Western countries as a background before the explanation. This kind of teaching method not only enhances students' interest in learning English, but also enables students to understand the cultural background of Western countries. In addition, in the process of text explanation, if the text involves historical events and customs, at this time, teachers should expand the content involved in the text. In the process of vocabulary explanation, not only should the word meaning and the part of speech be explained, but also the meaning of the environment and the meaning of the word in different contexts are different ${ }^{[3]}$. Chinese culture is related to farming culture in the process of development. The origin of Western language and culture is mostly related to the ocean and outward expansion. Chinese is usually expressed in relation to farming, while Western expression is related to ocean expansion. For example, in Chinese, 海纳百川, the corresponding English is' All rivers run into sea'. In Chinese, bragging and lying are the same, and the corresponding English is expressed as A boaster and a liar are cousins-german. If you don't understand the culture of English-speaking countries, you can have unnecessary troubles in your daily life. For instance, a school leader introduces a new American teacher to you, as follows: Ladies and gentlemen, I'm delighted to introduce to you a very pretty girl, Miss Brown. She is a very good teacher from the USA. The Chinese first met and liked to praise each other, and the Americans thought that the first time they met, they should not be objectively evaluated, especially the use of Good and Pretty would make American teachers feel very embarrassed. The correct English introduction should be: Ladies and gentlemen, I'm delighted to introduce to you a new teacher from the USA, Miss Ann Brown. She is a doctor of American Literature with rich experience in English teaching.

Organize extracurricular cultural practice activities. Teachers should encourage students to read culturally-oriented English periodicals and books. If conditions permit, students can collect English movies, English songs, etc., and organize extracurricular activities such as English competitions and English drama shows. It not only enables students to deepen their understanding of Western culture, but also to experience cultural communication and enhance students' cross-cultural communication awareness ${ }^{[4]}$.

Schools can make changes in the curriculum. In addition to traditional language teaching, we should set up an introduction to Western culture, use the cultural profiles of English-speaking countries and the introduction of intercultural communication and other related subjects. Students can learn more about other countries' cultures and be able to speak with their own languages. Distinguish from culture and improve the ability to capture culture.

Regular cultural seminars will be held. Schools can formulate detailed lectures on Western culture according to the characteristics of the curriculum of the Institute. Experts and scholars from English-speaking countries should be invited to give lectures on English culture, through explanation, comparison, analysis and discussion. In a variety of ways, the English culture is interpreted in all aspects, and the cultural differences between English-speaking countries and national cultural differences are analyzed, which has aroused students' interest in learning ${ }^{[5]}$.

\subsection{Improve English teachers' cross-cultural education beliefs and their own cross-cultural literacy}

Students will use the teacher's behavior as a benchmark, while the teacher's philosophy and behavior can influence students. Teachers not only have excellent professional qualities, but also have good beliefs. Teachers are the leaders, organizers and practitioners in the whole learning process. The content of students' learning depends to a large extent on the individual teachers. Only teachers 
can fully recognize the importance of intercultural communication and enable students to be aware of this importance. The understanding of the importance of communication can be improved, teachers can always cross the intercultural communication content throughout the teaching, and the cultivation of students' consciousness is subtle ${ }^{[6]}$. The teacher's own cross-cultural literacy is especially important for cultivating students' awareness of intercultural communication. After a large number of investigations, if English teachers live or study in English-speaking countries, teachers can master the relevant culture of English-speaking countries. However, most English teachers have never lived in English-speaking countries and result in a relatively lack of knowledge of English cultural knowledge. So it's hard for them to cultivate students' intercultural communication skills. Most of the teachers have the following problems in cross-cultural knowledge education. The teachers have insufficient knowledge about the cultural knowledge of the English-speaking countries, and the concepts introduced to the students are all one-sided. Some teachers will reserve relevant cultural knowledge according to their personal interests and hobbies, leading the students to master. The culture is related to the teacher's preferences and is one-sided. At present, systematic cross-cultural training for teachers in China is an urgent problem to be solved. If school conditions permit, front-line English teachers should be sent abroad for study and research, so that the cultural literacy of English teachers can be further improved. .

\subsection{Make full use of the internet platform to expand cultural sources}

Teachers should guide students to make full use of the Internet. Internet can be used as an important auxiliary tool in English teaching. The Internet is the largest information resource and stores all kinds of rich resources around the world. Therefore, teachers should effectively guide learning to the Internet. The use of internet can effectively expand the knowledge of students, so that students' cultural communication awareness and ability can be improved accordingly ${ }^{[7]}$.

Establish an autonomous learning model through an English learning website. Foreign scholars pointed out that in the process of learning English, cross-cultural learning tasks can be completed by making full use of the Internet. The Internet is diverse and there are a large number of English learning websites. Teachers should recommend relevant English learning websites so that students can use the Internet to search for cultural information related to English-speaking countries, and expand relevant cultural knowledge from the website to enhance their cultural heritage. In the end, the goal of improving intercultural communication ability is achieved.

The network resources are coordinated with the classroom teaching. In the teaching process, the teachers also make full use of the network resources to collect video and audio related to the subject, and display the contents to the students through multimedia. The contents of the exhibition mainly include the customs, history, political background, etc of the English-speaking countries. This kind of teaching method can also make up for the shortcomings of lack of cross-cultural knowledge ${ }^{[8]}$.

\section{Conclusion}

The cultivation of intercultural communication competence in English teaching is the top priority of current education. It should be used to make use of internet technology, change the traditional thinking mode of teachers, pay attention to cross-cultural communication education and the expansion of English cultural knowledge, and improve the cross-culture of English learners. This is of great significance to improve the students' intercultural communication competence

\section{References}

[1] Liu Wei, Du Jingfen, Gao Yueqin. Cultivation of Intercultural Communication Ability in English Teaching under the 
Background of "Cultural Going Out". Education and Occupation,Vol. 1 (2016) No. 25, p.13-36.

[2] Cai Haiyan. Cultivation of Intercultural Communication Ability in English Teaching of Higher Vocational Colleges under the Background of "Cultural Going Out". English Plaza,Vol. 7 (2017) No. 25, p.59-60.

[3] Li Shufang. Foreign Language Teaching and Intercultural Communication Ability Cultivation. Modern Education, Vol. 3 (2016) No. 25, p.15-16.

[4] Pang Lingjuan, Huang Yuhua. Application of Micro-curriculum with Chinese Culture as the Theme in the Cultivation of Intercultural Communication Ability. Overseas English,Vol. 4 (2017) No. 25, p.90-91.

[5] Xu Lixin. Research on the Reform of College English Teaching in Local Universities under the Strategy of "Going Global Culture Goes Out". Journal of Xingtai University,Vol. 1 (2018) No. 61, p.153-154.

[6] Liu Xiulian, Zhou Wei, He Jin. Investigation and Research on the Status Quo of Chinese Cultural English Expression in College Students' Intercultural Communication. New Curriculum Learning,Vol. 4 (2014) No. 25, p.25-26.

[7] Peng Yu. Research on College English Culture Teaching under the Strategy of "Going Global Culture Goes Out"--Analysis and Research Based on the New Translation Types of College English 46th Grade. Journal of Yunmeng City,Vol. 4 (2015) No. 23, p.144-148.

[8] Leng Jinying. Exploring how Chinese cultural translation can be integrated into college English teaching. Win the Future,Vol. 4 (2017) No. 21, p.0017-0017. 